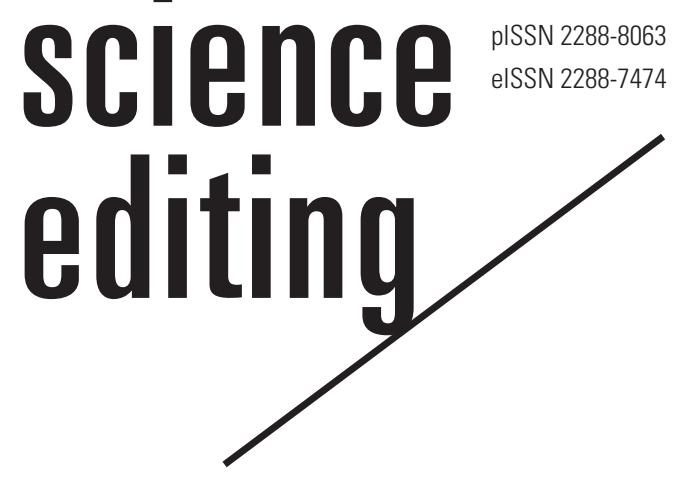

\title{
Historical diagnostic and therapeutic changes of ischemic stroke based on the highly cited articles
}

\author{
Yerim Kim', Dae Young Yoon², Jee-Eun Kim³, Ju-Hun Lee', Hong-Ki Song', Jong Seok Bae' \\ Departments of ${ }^{1}$ Neurology and ${ }^{2}$ Radiology, Kangdong Sacred Heart Hospital, Hallym University College of Medicine, Seoul; \\ ${ }^{3}$ Department of Neurology, Seoul Medical Center, Seoul, Korea
}

Abstract

Purpose: Stroke is a global economic burden of health, which means that it is critical to evaluate changes of optimal diagnoses and treatments. The aim of the study reported herein was to identify the most-cited articles in the field of ischemic stroke and assess their characteristics.

Methods: We searched all included articles that had been cited more than 100 times using the "Cited Reference Search" in February 2016 from Web of Science Core Collection. Among a total of 2,651 articles, we excluded articles on basic science and which involved only hemorrhagic strokes and identified the top-100 cited articles on ischemic stroke.

Results: The number of citations for the articles analyzed in this study ranged from 5,182 to 580 . Most of the articles were published in The Lancet (25\%) and Stroke (23\%), and originated from the United States of America $(n=44)$. Most of them were original articles $(65 \%)$ and dealt with stroke risk factors (32\%) and stroke management (30\%). A novel study of hyperacute treatment involving recombinant-tissue plasminogen activator was described in the top-ranked article. Conclusion: Reviews on highly cited articles can help physicians identify trends in the diagnosis and treatment of ischemic stroke in the past. This bibliometric analysis can provide a unique perspective on historical developments in this field.

Keywords

Bibliometrics; Cerebral infarction; Ischemic stroke; Stroke

ORCID

Yerim Kim

https://orcid.org/0000-0002-7108-6302

Dae Young Yoon

https://orcid.org/0000-0003-1522-0236

Jee-Eun Kim

https://orcid.org/0000-0002-3811-3479

Ju-Hun Lee

https://orcid.org/0000-0001-6831-7248

Hong Ki Song

https://orcid.org/0000-0001-8917-4979

Jong Seok Bae

https://orcid.org/0000-0002-4313-1786

\section{Introduction}

Stroke is a disastrous disease with high mortality and morbidity rates that represent a global economic burden of health. Moreover, the ever-increasing size of the elderly population is likely to substantially increase the stroke burden within the near future. One epidemiological study of stroke have found that ischemic stroke (IS) accounts for approximately $76.1 \%$ of all types of strokes [1]. Since stroke has a heterogeneous pathophysiology and evolving treatment meth- 
ods, the ability to evaluate stroke diagnoses and treatments is important to the clinical outcomes.

A surrogate for the impact of a new reported finding in a scientific field is the number of times that the article has been cited (the citation count). The Science Citation Index was started by the Institute for Scientific Information (ISI) with the purpose of providing a systematic ongoing measurement of the citation counts for scientific journals [2]. The number of citations might be useful for quantifying the influence of an article in its field, although the value of citation indices is still debated [2]. Numerous studies have analyzed the mostcited articles in various medical fields, including neurosurgery [3], general surgery [4], orthopedics [5], and radiology [6]. However, a bibliometric analysis of the most-cited articles in the field of stroke has not been reported previously.

The purpose of this study was to investigate which of the studies received high citations in the field of IS because reviews on highly cited articles can help physicians identify trends in the diagnosis and treatment of IS.

\section{Methods}

To identify the most-cited IS articles, journals listed under the following categories of the ISI Web of Knowledge Journal Citation Reports Science Edition 2014 (Thomson Reuters, New York, NY, United States of America) were assessed for inclusion "clinical neurology" (192 journals), "neuroscience" (252 journals), and "medicine, general \& internal" (154 journals). The category of "medicine, general $\&$ internal" was included because it covers journals with high impact-factor that contain a diffuse variety of papers that span miscellaneous fields. We searched all included articles that had been cited more than one-hundred times using the "Cited Reference Search" (Thomson Reuters) in February 2016. The ISI Web of Knowledge-Web of Science provides the overall citation counts for published scientific articles since 1945.

To identify IS journals, we searched for the following terms either singly or in combination: "cerebral infarction," "cerebral ischemia," "cerebrovascular disease," "cerebrovascular ischemia," "stroke," "cerebral thrombosis," "cerebral embolism," "cerebral thromboembolism," "brain ischemia," "brain infarction," "brain embolism," "brain thromboembolism," "cerebrovascular insufficiency," "lacunar infarction," "malignant infarction," and "central nervous system infarction." Among a total of 2,651 articles, we excluded 30 that appeared to be duplicate in the analyzed journals. We also excluded articles on basic science based on animal models and which involved only hemorrhagic strokes.

We reviewed the following categories of the journals: title, publication date, country of publication, institution of publi- cation, department, authorship, number of citations, subtype of article (guidelines, original article, stroke classification and scale, systematic review or meta-analysis, review or editorial, or national registry), and main topic. The author information of the articles was defined as those of the first author. If the first author had duplex affiliations, the correspondent's one was used. If the first author was involved in a group and the first or corresponding author was not presented clearly, we did not asses the first or corresponding author, institution, or country. Institutional review board approval was unnecessary since we conducted a bibliometric analysis of existing published articles that did not contain human subjects.

\section{Results}

We finally identified the most frequently cited 100 articles from the Web of Science Core Collection (Table 1 and Suppl. 1). The most-cited article was cited 5,182 times, while the least-cited article was cited 580 times. The National Institute of Neurological Disorders and Stroke (NINDS) r-tPA Stroke Trial published the top-ranking article in 1995 , which was a randomized clinical controlled trial that demonstrated the effect of tissue plasminogen activator (tPA) on acute IS [7]. The number of citations annually ranged from 17.3 to 426.5 , and approximately one-third of the articles were cited more than 1,000 times. The article with the most annual citations since publication was a guideline for the early management of patients with acute IS from the American Heart Association/ American Stroke Association (AHA/ASA) that was published in 2013 [8].

Only 16 journals provided the top-100 articles in our bibliometric analysis of IS (Table 2). Of the 16 journals, The Lancet $(\mathrm{n}=25)$, Stroke $(\mathrm{n}=23)$, New England Journal of Medicine $(\mathrm{n}=17)$, and Journal of the American Medical Association $(\mathrm{n}=12)$ contained the majority of the articles. The articles were published from 1977 to 2013 (Fig. 1). Most of the top100 cited articles on IS originated from the United States of America $(\mathrm{n}=44)$, followed by the United Kingdom $(\mathrm{n}=16)$ (Suppl. 2). The most-represented departments were the Department of Neurology, University of California $(n=5)$ and the Department of Clinical Medicine, University of Oxford $(\mathrm{n}=5)$ (Suppl. 3). The author with the most contributions was Hacke W ( $\mathrm{n}=12)$, followed by Wolf PA $(\mathrm{n}=7)$ (Table 3$)$.

There were 65 original articles and 13 systematic reviews/ meta-analyses (Table 4). The main topics included "stroke risk factors" $(\mathrm{n}=33)$, "stroke registry" $(\mathrm{n}=3)$, "stroke review" $(\mathrm{n}=3)$, "stroke guidelines" $(\mathrm{n}=6)$, "stroke diagnosis, pathophysiology" ( $n=15)$, "stroke management" $(\mathrm{n}=32)$, and "stroke prognosis" $(\mathrm{n}=8)$ (Table 5$)$. The most frequently described topics about "stroke risk factors" in our analysis were atri- 
Table 1. The top-10 cited articles on ischemic stroke $\mathrm{e}^{\text {a) }}$

\begin{tabular}{|c|c|c|c|c|}
\hline Rank & Article & $\begin{array}{l}\text { No. of } \\
\text { citations }\end{array}$ & $\begin{array}{l}\text { No. of annual } \\
\text { citations }\end{array}$ & $\begin{array}{l}\text { No. of annual } \\
\text { citations, rank }\end{array}$ \\
\hline 1 & $\begin{array}{l}\text { Marler JR, Brott T, Broderick J, et al. Tissue plasminogen activator for acute ischemic stroke. } \\
\text { N Engl J Med 1995;333:1581-8. }\end{array}$ & 5,182 & 259.1 & 3 \\
\hline 2 & $\begin{array}{l}\text { Adams HP Jr, Bendixen BH, Kappelle LJ, et al. Classification of subtype of acute ischemic } \\
\text { stroke: definitions for use in a multicenter clinical trial.. Stroke 1993;24:35-41. }\end{array}$ & 3,673 & 159.7 & 8 \\
\hline 4 & $\begin{array}{l}\text { O'Leary DH, Polak JF, Kronmal RA, et al. Carotid-artery intima and media thickness as a risk } \\
\text { factor for myocardial infarction and stroke in older adults. N Engl J Med 1999;340:14-22. }\end{array}$ & 2,862 & 168.4 & 7 \\
\hline 5 & $\begin{array}{l}\text { MacMahon S, Peto R, Cutler J, et al. Blood pressure, stroke, and coronary heart disease. Part } \\
\text { 1, Prolonged differences in blood pressure: prospective observational studies corrected for } \\
\text { the regression dilution bias. Lancet 1990;335:765-74. }\end{array}$ & 2,847 & 113.9 & 21 \\
\hline 7 & $\begin{array}{l}\text { Go AS, Hylek EM, Phillips KA, et al. Prevalence of diagnosed atrial fibrillation in adults: } \\
\text { national implications for rhythm management and stroke prevention: the AnTicoagulation } \\
\text { and Risk Factors in Atrial Fibrillation (ATRIA) Study. JAMA 2001;285:2370-5. }\end{array}$ & 2,507 & 179.1 & 5 \\
\hline 8 & $\begin{array}{l}\text { Probstfield JL. Prevention of stroke by antihypertensive drug treatment in older persons with } \\
\text { isolated systolic hypertension: final results of the Systolic Hypertension in the Elderly } \\
\text { Program (SHEP). JAMA 1991;265:3255-64. }\end{array}$ & 2,382 & 99.3 & 30 \\
\hline 9 & $\begin{array}{l}\text { Hacke W, Kaste M, Bluhmki E, et al. Thrombolysis with alteplase } 3 \text { to } 4.5 \text { hours after acute } \\
\text { ischemic stroke. N Engl J Med 2008;359:1317-29. }\end{array}$ & 2,221 & 317.3 & 2 \\
\hline 10 & $\begin{array}{l}\text { Sever PS, Dahlöf B, Poulter NR, et al. prevention of coronary and stroke events with } \\
\text { atorvastatin in hypertensive patients who have average or lower-than-average cholesterol } \\
\text { concentrations, in the Anglo-Scandinavian Cardiac Outcomes Trial--Lipid Lowering } \\
\text { Arm (ASCOT-LLA): a multicentre randomised controlled trial. Lancet 2003;361:1149-58. }\end{array}$ & 2,160 & 180.0 & 4 \\
\hline
\end{tabular}

a) See Suppl. 1 for all 100 articles.

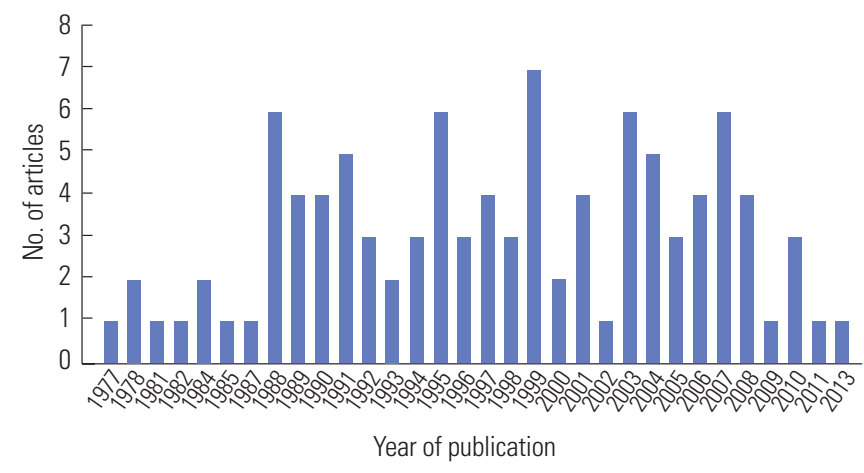

Fig. 1. Most popular articles cited by decade.

al fibrillation $(\mathrm{n}=5)$, hypertension $(\mathrm{n}=4)$, dyslipidemia $(\mathrm{n}=4)$, and coagulopathy $(\mathrm{n}=4)$, while those about "stroke management" were $\mathrm{PAA}(\mathrm{n}=9)$ and antithrombotic therapy $(\mathrm{n}=10)$.

\section{Discussion}

We analyzed the top-100 cited articles in the field of IS. The top-ranked article was a report of the NINDS r-tPA Stroke Trial demonstrating the effect of r-tPA on acute IS in 1995 for the first time [7]. The article with the most citations annually was a guideline for the early management of patients with acute IS from the AHA/ASA that was published in 2013 [8]. Original articles accounted for two-thirds of the 100 articles. The top-ranked main topics were "stroke risk factors" and "stroke management."

Many randomized controlled trials have resulted in landmark articles on acute treatments of IS. The NINDS r-tPA Stroke Trial has since 1995 (1; the parenthesized italicized numbers refer to the rank in Table 1) been the most influential trial in the field of IS. r-tPA is the only method used to recanalize occlusive arteries in patients with hyperacute IS. Despite an increased rate of symptomatic intracerebral hemorrhage (ICH), intravenous r-tPA within 3 hours of the onset of 
Table 2. Journals in which the top-100 cited articles were published

\begin{tabular}{llc}
\hline Rank & \multicolumn{1}{c}{ Journal } & $\begin{array}{c}\text { No. of } \\
\text { articles }\end{array}$ \\
\hline 1 & The Lancet & 25 \\
2 & Stroke & 23 \\
3 & New England Journal of Medicine & 17 \\
4 & JAMA: Journal of the American Medical Association & 12 \\
5 & Annals of Neurology & 4 \\
6 & Neurology & 4 \\
7 & Archives of Internal Medicine & 3 \\
8 & Lancet Neurology & 3 \\
9 & Annals of Internal Medicine & 2 \\
10 & Brain & 1 \\
11 & Cerebrovascular Diseases & 1 \\
12 & Journal of Cerebral Blood Flow and Metabolism & 1 \\
13 & Journal of Neurology Neurosurgery and Psychiatry & 1 \\
14 & Journal of the Neurological Sciences & 1 \\
15 & Nature Reviews Neuroscience & 1 \\
16 & Trends in Neurosciences & 1 \\
\hline & & \\
\hline
\end{tabular}

Table 3. Authors who contributed at least 5 of the top-100 cited ischemic stroke articles

\begin{tabular}{llcl}
\hline Rank & Author & $\begin{array}{c}\text { No. of top-100 } \\
\text { cited articles }\end{array}$ & $\begin{array}{c}\text { Types of author association } \\
\text { according to number of } \\
\text { top-100 cited articles }\end{array}$ \\
\hline 1 & Hacke W & 12 & First $(n=6)$, corresponding $(n=6)$ \\
2 & Wolf PA & 7 & First $(n=4)$, corresponding $(n=3)$ \\
3 & Bamford J & 4 & First $(n=2)$, corresponding $(n=2)$ \\
3 & del Zoppo GJ & 4 & First $(n=2)$, corresponding $(n=2)$ \\
3 & Feigin VL & 4 & First $(n=2)$, corresponding $(n=2)$ \\
3 & Smith WS & 4 & First $(n=2)$, corresponding $(n=2)$ \\
\hline
\end{tabular}

Articles from specific groups whose first or corresponding authors could not be determined (article no. 3, 17, 18, 22, 25, 28, 38, 39, 46, 50, 51, 54, 68, 79, 80 , and 85 are excluded from this table.

Table 4. Types of the top-100 cited ischemic stroke articles

\begin{tabular}{lc}
\hline Type of article & No. of articles \\
\hline Original article & 65 \\
Guidelines & 6 \\
Stroke classification or stroke related scale & 6 \\
Review article or editorial & 7 \\
Systematic review or meta-analysis & 13 \\
National registry & 3 \\
\hline
\end{tabular}

Table 5. Main topics covered in the top-100 cited ischemic stroke articles

\begin{tabular}{rr}
\hline No. of \\
articles
\end{tabular}

Stroke risk factor

Multiple risk factor 3

Hypertension or blood pressure $\quad 4$

Diabetes mellitus 1

Dyslipidemia or statin therapy 4

Atrial fibrillation 5

Coagulopathy (fibrinogen, factor $\mathrm{V}$, sickle cell anemia, estrogen) 4

Carotid artery or aortic arch stenosis 2

Homocysteine 3

Diet (vitamin, fruit, alcohol, etc.) 3

Obstructive sleep apnea

Patent foramen ovale 1

C-reactive protein 1

Inflammatory mediator 1

Published guidelines $\quad 6$

Stroke registry 3

Stroke review 3

Stroke diagnosis, pathophysiology

Pathophysiology 6

Subtype classification 3

Scale (mRS, NIHSS, etc.) 3

Imaging modalities 3

Stroke management

Tissue plasminogen activation (intravenous-tPA) 9

Thrombolysis (intraarterial-urokinase, desmoteplase) 3

Mechanical thrombectomy 1

Decompression surgery 1

Bypass surgery 1

Carotid endarterectomy 1

Antithrombotic therapy (aspirin, clopidogrel, dypiridamole, ticlopidine) 10

Warfarin or anticoagulation 6

Stroke prognosis

Dementia 1

Mood 1

Rehabilitation 1

Reorganize or recovery 5

IS reportedly improves short-term outcomes [7]. That article prompted the use of r-tPA to spread worldwide and become accepted as the appropriate management in patients with hy- 


\section{science editing /}

peracute stroke. It is remarkable that an article that is more than 20 years old is still being cited continuously, which has resulted in it being ranked third in the overall annual citation rankings (Table 1). Furthermore, the European Cooperative Acute Stroke Study (ECASS) III trial showed significant efficacy of r-tPA when it is administered for up to 4.5 hours [9]. The SITS-MOST (Safe Implementation of Thrombolysis in Stroke-Monitoring Study) (44) evaluated the safety and efficacy of r-tPA at both 3 and 4.5 hours [10]. Current guidelines recommend that r-tPA should be administered to eligible patients for up to 4.5 hours after symptom onset or the last known normal time. However, the ECASS I (13) and ECASS II (20) trials did not demonstrate significant efficacy on the mortality rate at 30 days or the overall incidence of intracerebral hemorrhage in IS patients with r-tPA compared to placebo treatment $[11,12]$. However, we assume that administering r-tPA at a dose of $1.1 \mathrm{mg} / \mathrm{kg}$ (in ECASS I) and at an injection time of within 6 hours after stroke onset (in both ECASS I and II) might have influenced the results. This shows the importance of reporting on both negative and positive studies.

The numerous studies aimed at proving the efficacy of various types of thrombolysis therapy have presumably involved physicians actively applying acute IS treatments. A randomized trial that tested the recanalization efficacy of recombinant prourokinase demonstrated that the intra-arterial administration of prourokinase within 6 hours after stroke onset was associated with better recanalization and a good clinical outcome at 90 days of acute IS (a phase II randomized trial of recombinant pro-urokinase by direct arterial delivery in acute middle cerebral artery stroke [PROACT], 66; intra-arterial prourokinase for acute ischemic stroke [PROACT II], 15) $[13,14]$. Administering another promising thrombolysis drug, desmoteplase, at 3 to 9 hours after acute symptom onset was associated with a higher incidence of reperfusion in IS patients (Desmoteplase in Acute Ischemic Stroke trial, 78) [15]. Advancements in techniques and materials are leading to endovascular thrombectomy emerging for the management of acute IS. In reflecting these trends, two articles on the Merci Retriever, a device used for mechanical clot extraction in cerebral arteries, were included in our study $(60,74)$. Although the recanalization rate was higher for a newer-generation device than for first-generation ones, these differences were not statistically significant. Other devices used for mechanical thrombectomy such as the Trevo and Solitaire stents were not listed in our top-100 cited articles. Since the results will be related to the development of the order of retriever, such articles might become more common in the near future. Despite the absence of the subsequent related articles, the Extending the time for Thrombolysis in Emergency Neurological Deficits with Intra-Arterial therapy (EXTEND-IA) trial (206 citations)
[16], Endovascular Treatment for Small Core and Proximal Occlusion Ischemic Stroke trial (ESCAPE) (214 citations) [17], and Multicenter Randomized Clinical Trial of Endovascular Treatment for Acute Ischemic Stroke (MR CLEAN) study in the Netherlands (271 citation) [18] were the most prominent findings in the field of IS in 2015. These articles reported on the effectiveness of mechanical thrombectomy and might be milestones in the acute management of acute IS. This led to the AHA/ASA association updating the guidelines for the early management of patients with acute IS regarding endovascular treatment in 2015 [19].

Regarding antithrombotic agents for the prevention of IS, the International Stroke Trial (32) suggested that aspirin was both safer and more effective than heparin in acute IS [20]. Except in embolic stroke, the efficacy of heparin for preventing IS has not been studied. The poor preventive effect on IS has resulted in physicians trying more aggressive treatments such as using dual antiplatelets. However, unlike in cardiac research, dual antiplatelet therapy does not significantly reduce major vascular events and is associated with major bleeding events (management of atherothrombosis with clopidogrel in high-risk patients with recent transient ischaemic attack or ischaemic stroke [MATCH] trial, 31) [21]. However, considering the findings of the Clopidogrel in High-risk Patients with Acute Non-disabling Cerebrovascular Events (CHANCE) trial, current guidelines recommend that the combination of aspirin and clopidogrel can be initiated within 24 hours of a minor IS or transient ischemic attack and continued for 21 days.

Stroke classifications/scales and national registries have been used as references (stroke classifications/scales, $n=6$; national registries, $n=3$ ). These articles included the Trial of Org 10172 in Acute Stroke Treatment classification (2), and have provided important methodologies for the clinical research of strokes.

Five of the six guidelines related to IS were published in the journal Stroke. Guidelines for the early management of patients with IS were published in 2003 (80), 2007 (25), and 2013 (50), with the last being the most-cited article annually $[8,22,23]$. Guidelines for preventing IS or transient ischemic attack were published in 2006 (38) and 2011 (54) [24,25]. An especially notable finding is that recent guidelines were cited more frequently, which is attributable to physicians focusing more on treating patients using evidence-based guidelines nowadays. With regard to the publication patterns, many of the randomized controlled trials were published in New England Journal of Medicine, and most of the guidelines in patients with IS were published in Stroke.

This study was subject to some limitations. First, there may be numerous biases, including self-citations, journal citations with higher impact-factor, country parochialism, inhouse ci- 
tations, language bias (English journal-oriented citation), and omission bias. Second, "obliteration by incorporation" is a major problem. As precious knowledge becomes generalized, physicians no longer need to cite the paper [26]. Third, the method used to calculate the number of total citations might be affected by the duration since article-publication, which is why we added the rank based on the number of annual citations. Finally, articles on trials that evaluated stroke as one of multiple endpoints were not included in this bibliometric analysis. Because this "Cited Reference Search" facility searches for titles of articles, it might have resulted in the omission of relevant articles that were published in various medical journals. For example, although most of the large randomized multicenter trials of novel oral anticoagulants other than edoxaban (Effective Anticoagulation with Factor Xa Next Generation in Atrial Fibrillation-Thrombolysis in Myocardial Infarction 48 [ENGAGE AF-TIMI 48], 384 citations) were cited more than 1,700 times (Randomized Evaluation of Long-term Anticoagulation Therapy [RE-LY] trial, 3,152 citations; Rivaroxaban Once Daily Oral Direct Factor Xa Inhibition Compared with Vitamin K Antagonism for Prevention of Stroke and Embolism Trial in Atrial Fibrillation [ROCKET AF], 1,914 citations; and Apixaban for Reduction in Stroke and Other Thromboembolic Events in Atrial Fibrillation [ARISTOTLE] trial, 1,702 citations), these were not included in the present lists. However, we tried to identify many journals on IS and evaluated various fields: "medicine, general \& internal," "neuroscience," and "clinical neurology." Our main purpose was to identify trends in clinical decision-making in neurological sciences. Although citation statistics might have some critical limitations, analyzing citation rates might provide a unique perspective of historical diagnostic and therapeutic changes in the field of IS. By identifying trends in the diagnosis and treatment of IS in the past, physicians will be able to develop new ideas or new plan.

\section{Conflict of Interest}

No potential conflict of interest relevant to this article was reported.

\section{Acknowledgements}

Jong Seok Bae: This research was supported by the Basic Science Research Program through the National Research Foundation of Korea (NRF) funded by the Ministry of Education (grant NRF-2017R1D1A1B03029672).

Yerim Kim: This research was supported by the Basic Science Research Program through the National Research Foundation of Korea (NRF) funded by the Ministy of Science and ICT (NRF-2018R1C1B5086320) and supported by a grant no.
2019-08 from the Kangdong Sacred Heart Hospital Fund.

\section{Supplementary Material}

Supplementary file is available from https://doi.org/10.6087/ kcse.211

Suppl. 1. The top-100 cited articles on ischemic stroke

Suppl. 2. Countries of origin of the top-100 cited articles

Suppl. 3. Institutions most frequently represented in the top-cited articles

\section{References}

1. Hong KS, Bang OY, Kang DW, et al. Stroke statistics in Korea: part I. Epidemiology and risk factors: a report from the korean stroke society and clinical research center for stroke. J

Stroke 2013;15:2-20. https://doi.org/10.5853/jos.2013.15.1.2

2. Moed HF. New developments in the use of citation analysis in research evaluation. Arch Immunol Ther Exp (Warsz) 2009;57:13-8. https://doi.org/10.1007/s00005-009-0001-5

3. Ponce FA, Lozano AM. Highly cited works in neurosurgery. Part I: the 100 top-cited papers in neurosurgical journals. J Neurosurg 2010;112:223-32. https://doi.org/10.3171/2009.12. JNS091599

4. Paladugu R, Schein M, Gardezi S, Wise L. One hundred citation classics in general surgical journals. World J Surg 2002;26:1099-105. https://doi.org/10.1007/s00268-0026376-7

5. Kelly JC, Glynn RW, O’Briain DE, Felle P, McCabe JP. The 100 classic papers of orthopaedic surgery: a bibliometric analysis. J Bone Joint Surg Br 2010;92:1338-43. https://doi. org/10.1302/0301-620X.92B10.24867

6. Yoon DY, Yun EJ, Ku YJ, et al. Citation classics in radiology journals: the 100 top-cited articles, 1945-2012. AJR Am J Roentgenol 2013;201:471-81. https://doi.org/10.2214/ AJR.12.10489

7. National Institute of Neurological Disorders and Stroke rtPA Stroke Study Group. Tissue plasminogen activator for acute ischemic stroke. N Engl J Med 1995;333:1581-7. https://doi.org/10.1056/NEJM199512143332401

8. Jauch EC, Saver JL, Adams HP Jr, et al. Guidelines for the early management of patients with acute ischemic stroke: a guideline for healthcare professionals from the American Heart Association/American Stroke Association. Stroke 2013;44:870-947. https://doi.org/10.1161/ STR.0b013e318284056a

9. Hacke W, Kaste M, Bluhmki E, et al. Thrombolysis with alteplase 3 to 4.5 hours after acute ischemic stroke. N Engl J Med 2008;359:1317-29. https://doi.org/10.1056/NEJMoa0804656 
10. Wahlgren N, Ahmed N, Davalos A, et al. Thrombolysis with alteplase for acute ischaemic stroke in the Safe Implementation of Thrombolysis in Stroke-Monitoring Study (SITSMOST): an observational study. Lancet 2007;369:275-82. https://doi.org/10.1016/S0140-6736(07)60149-4

11. Hacke W, Kaste M, Fieschi C, et al. Intravenous thrombolysis with recombinant tissue plasminogen activator for acute hemispheric stroke. The European Cooperative Acute Stroke Study (ECASS). JAMA 1995;274:1017-25.

12. Hacke W, Kaste M, Fieschi C, et al. Randomised doubleblind placebo-controlled trial of thrombolytic therapy with intravenous alteplase in acute ischaemic stroke (ECASS II). Second European-Australasian Acute Stroke Study Investigators. Lancet 1998;352:1245-51. https://doi.org/10.1016/ s0140-6736(98)08020-9

13. del Zoppo GJ, Higashida RT, Furlan AJ, Pessin MS, Rowley HA, Gent M. PROACT: a phase II randomized trial of recombinant pro-urokinase by direct arterial delivery in acute middle cerebral artery stroke. PROACT Investigators. Prolyse in Acute Cerebral Thromboembolism. Stroke 1998;29:4-11. https://doi.org/10.1161/01.str.29.1.4

14. Furlan A, Higashida R, Wechsler L, et al. Intra-arterial prourokinase for acute ischemic stroke. The PROACT II study: a randomized controlled trial. Prolyse in Acute Cerebral Thromboembolism. JAMA 1999;282:2003-11. https://doi.org/10.1001/jama.282.21.2003

15. Hacke W, Albers G, Al-Rawi Y, et al. The Desmoteplase in Acute Ischemic Stroke Trial (DIAS): a phase II MRI-based 9-hour window acute stroke thrombolysis trial with intravenous desmoteplase. Stroke 2005;36:66-73. https://doi. org/10.1161/01.STR.0000149938.08731.2c

16. Campbell BC, Mitchell PJ, Kleinig TJ, et al. Endovascular therapy for ischemic stroke with perfusion-imaging selection. N Engl J Med 2015;372:1009-18. https://doi.org/10.1056/ NEJMoa1414792

17. Goyal M, Demchuk AM, Menon BK, et al. Randomized assessment of rapid endovascular treatment of ischemic stroke. N Engl J Med 2015;372:1019-30. https://doi.org/10.1056/ NEJMoa1414905

18. Berkhemer OA, Fransen PS, Beumer D, et al. A randomized trial of intraarterial treatment for acute ischemic stroke. N Engl J Med 2015;372:11-20. https://doi.org/10.1056/NEJMoa1411587

19. Powers WJ, Derdeyn CP, Biller J, et al. 2015 American Heart Association/American Stroke Association Focused Update of the 2013 Guidelines for the Early Management of Patients With Acute Ischemic Stroke Regarding Endovascular Treatment: A Guideline for Healthcare Profes- sionals From the American Heart Association/American Stroke Association. Stroke 2015;46:3020-35. https://doi. org/10.1161/STR.0000000000000074

20. The International Stroke Trial (IST): a randomised trial of aspirin, subcutaneous heparin, both, or neither among 19435 patients with acute ischaemic stroke. International Stroke Trial Collaborative Group. Lancet 1997;349:156981.

21. Diener HC, Bogousslavsky J, Brass LM, et al. Aspirin and clopidogrel compared with clopidogrel alone after recent ischaemic stroke or transient ischaemic attack in high-risk patients (MATCH): randomised, double-blind, placebo-controlled trial. Lancet 2004;364:331-7. https://doi.org/10.1016/ S0140-6736(04)16721-4

22. Adams HP Jr, Adams RJ, Brott T, et al. Guidelines for the early management of patients with ischemic stroke: A scientific statement from the Stroke Council of the American Stroke Association. Stroke 2003;34:1056-83. https://doi. org/10.1161/01.STR.0000064841.47697.22

23. Adams HP Jr, del Zoppo G, Alberts MJ, et al. Guidelines for the early management of adults with ischemic stroke: a guideline from the American Heart Association/American Stroke Association Stroke Council, Clinical Cardiology Council, Cardiovascular Radiology and Intervention Council, and the Atherosclerotic Peripheral Vascular Disease and Quality of Care Outcomes in Research Interdisciplinary Working Groups: the American Academy of Neurology affirms the value of this guideline as an educational tool for neurologists. Stroke 2007;38:1655-711. https://doi.org/10.1161/STROKEAHA.107.181486

24. Sacco RL, Adams R, Albers G, et al. Guidelines for prevention of stroke in patients with ischemic stroke or transient ischemic attack: a statement for healthcare professionals from the American Heart Association/American Stroke Association Council on Stroke: co-sponsored by the Council on Cardiovascular Radiology and Intervention: the American Academy of Neurology affirms the value of this guideline. Stroke 2006;37:577-617. https://doi.org/10.1161/01. STR.0000199147.30016.74

25. Furie KL, Kasner SE, Adams RJ, et al. Guidelines for the prevention of stroke in patients with stroke or transient ischemic attack: a guideline for healthcare professionals from the american heart association/american stroke association. Stroke 2011;42:227-76. https://doi.org/10.1161/ STR.0b013e3181f7d043

26. Garfield E. 100 citation classics from the Journal of the American Medical Association. JAMA 1987;257:52-9. 